\title{
Investigation of the Low Molecular Weight Thiol Composition in a Metastatic Prostate Cancer Cell Line (LNCaP) by LC-UV-MS and NMR after Labelling with the Ellman Reagent
}

\author{
Stephen Childs ${ }^{1}$, Nicolas Haroune ${ }^{1}$, Lee Williams ${ }^{1}$, Michael Gronow ${ }^{2 *}$ \\ ${ }^{1}$ Department of Pharmacy Health \& Well-Being, Faculty of Applied Sciences, University of Sunderland, Sciences Complex, \\ Sunderland, UK \\ ${ }^{2}$ Cambridge Cancer Research Fund, Cambridge, UK \\ Email: *michael@gronow-cambridge.co.uk
}

How to cite this paper: Childs, S., Haroune, N., Williams, L. and Gronow, M. (2017) Investigation of the Low Molecular Weight Thiol Composition in a Metastatic Prostate Cancer Cell Line (LNCaP) by LCUV-MS and NMR after Labelling with the Ellman Reagent. American Journal of Analytical Chemistry, 8, 1-18.

http://dx.doi.org/10.4236/ajac.2017.81001

Received: September 20, 2016

Accepted: January 1, 2017

Published: January 4, 2017

Copyright $\odot 2017$ by authors and Scientific Research Publishing Inc. This work is licensed under the Creative Commons Attribution International License (CC BY 4.0).

http://creativecommons.org/licenses/by/4.0/

\begin{abstract}
The low molecular weight thiols present in the deproteinized extract of a prostate cancer cell line (LNCaP-FGC) were analysed after derivatization with the Ellman reagent (ESSE). The mixed disulphides formed (RSSE) were fractionated, characterized and quantified by liquid chromatography on a C-18 column using UV detection. This revealed the presence, in femtomoles per cell, of glutathione $(8.30 \pm 0.73)$, cysteine $(2.71 \pm 0.04)$ and cysteinylglycine $(0.83 \pm 0.10)$, accounting for the bulk of the thiol present. Further analysis of the cell extracts using a novel and sensitive mass spectrometry technique allowed the detection of low level of an additional derivative which was identified as cysteinylglycerate using NMRspectroscopy.
\end{abstract}

\section{Keywords}

Prostate Cancer, Low Molecular Weight Thiols, Thiol Analysis, Ultra-High Performance Liquid Chromatography, Novel Thiol, LC-MS, NMR, Ellman's Reagent

\section{Introduction}

In the Western world, prostate cancer is a significant burden to men's health. It represents the most frequently diagnosed nondermatological malignancy and the second cause of death due to cancer in men [1] [2]. Fresh research on its genesis and detection is therefore a matter of some priority.

Currently, there is much interest in the role of oxidative stress in prostate 
cancer development and progression [for reviews see [3] and [4]]. Thiols play major roles and many important cellular metabolic processes and reactions [e.g. [5]]; in particular the low molecular weight thiols (LMWT) are responsible for the maintenance of oxidation/reduction (redox) levels in cells. The dynamic relationship between the LMWT, particularly glutathione (GSH), and reactive oxygen species (ROS) underpins redox regulation and signalling [6] [7]. With regard to prostate cancer, the recent work of Oberley's group [8] [9] has illustrated the role of cellular thiol components on the cell redox state and oxidative stress in the genesis and drug metabolism of prostate cancer cell lines.

It is therefore believed that further knowledge regarding the cellular metabolism of LMWT may help in the rational design of new more efficacious drugs to treat prostate cancer metastases.

Most studies on cellular LMWT have centred around the tripeptide GSH, the metabolism of which has been studied in detail over the last century and it is now widely accepted as the major LMWT present in eukaryote cells [10]. This tripeptide has been shown to have many roles in cellular metabolism; particularly with regard to its protective roles [11], cancer progression and chemoresistance [12].

However, earlier studies on the composition of tumor cell LMWT have revealed the presence of other thiols which could have important roles in tumor cell metabolism. Investigations on the LMWT found in the acid soluble fraction (ASF) of currently untreatable metastatic human prostate cancer cells indicated the presence of significant quantities of thiol components other than glutathione which were not identified [13]. In this paper, we report an in depth reinvestigation of these findings using more up to date techniques.

To facilitate this analysis and to avoid the formation of oxidation artefacts, the ASFthiols (RSH) have been labelled with the Ellman reagent (ESSE) [14] to give stable mixed disulfide derivatives (RSSE) [15] as shown in Figure 1.

The mixed disulfides (RSSE) formed from the LNCaP cell ASF were analysed and quantified by UHPLC-UV at $325 \mathrm{~nm}$. An unknown component was also detected in this system and identified by mass spectrometry and NMR spectroscopy.

\section{Materials and Methods}

\subsection{Chemicals}

L-cysteine (CYS), N-acetyl-cysteine (NAC), cysteinylglycine (CYSGLY), homocysteine (HCYS), cysteamine (CYSAM) and glutathione (GSH), 5'5 dithiobis

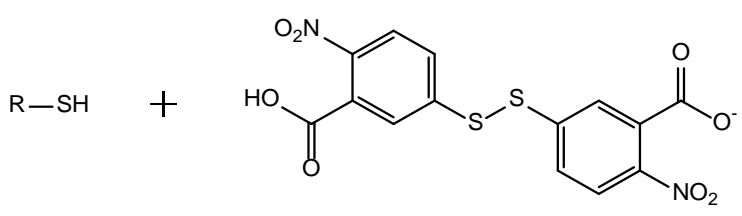

ESSE<smiles>[2H]SSc1ccc([N+](=O)[O-])c(C(=O)O)c1</smiles>

RSSE<smiles>O=C([O-])c1cc(S)ccc1[N+](=O)[O-]</smiles>

ES

(Yellow)

Figure 1. Reaction of the Ellman reagent (ESSE) with thiols (RSH). 
(-2-nitrobenzoic acid) (ESSE), trichloroacetic acid (TCA) and sodium phosphate were purchased from Sigma-Aldrich Ltd (Poole, Dorset, UK). All solutions were made using $18.2 \mathrm{~m} \Omega-\mathrm{cm}^{2}$ water, prepared on site by Diamond Lab Water System (Triple Red Laboratory Technology, Bucks, UK) LC-MS grade methanol was obtained from Fisher Scientific UK Ltd (Bishop Meadow Road, Loughborough.)

\subsection{Cell Culture}

A lymph node prostate cancer cell line (LNCaP, clone FGC-ECAC no. 89110211)) was supplied byPublic Health England (PHE) at Porton Down, UK. The cells were grown in RPMI 1640 medium supplemented with $2 \mathrm{mM}$ glutamine, $1 \mathrm{mM}$ sodium pyruvate and $10 \% \mathrm{v} / \mathrm{v}$ zone 2 foetal bovineserum. When at $80 \%$ confluence fresh medium was added and 2 hours later the cells were harvested with trypsin. After centrifuging the pellets down from the trypsin solution they were stored at $-80^{\circ} \mathrm{C}$ pending analysis.

\subsection{Preparation of Ellman Mixed Disulfides}

A) From known biological low molecular weight thiols

Stock solutions of GSH, CYS, CYSGLY, HCYS and NAC were prepared in $18.2 \mathrm{~m} \Omega-\mathrm{cm}^{2}$ water at an accurately known concentration (ca $2.0 \mathrm{mM}$ ). Calibration standards were prepared by mixing and then serially diluting the aqueous stock solutions. $350 \mu \mathrm{L}$ of diluted standard mixture was transferred to a $1.5 \mathrm{ml}$ micro-centrifuge tube. $50 \mu \mathrm{L}$ of internal standard solution was added to each tube followed by $400 \mu \mathrm{L}$ of $5 \mathrm{mM}$ ESSE solution (in $0.4 \mathrm{mM}$ phosphate buffer, $\mathrm{pH}$ 7.6). Each tube was vortexed briefly to mix the contents. $200 \mu \mathrm{L}$ of $50 \% \mathrm{w} / \mathrm{v}$ TCA was added and the tube was vortexed for 10 seconds then centrifuged at $14,000 \mathrm{rpm}$ at $+4^{\circ} \mathrm{C}$ for 20 minutes. The supernatant was collected and transferred to a LC vials in a cooled auto sampler $\left(+4^{\circ} \mathrm{C}\right)$ for injection. [It was found that analysis of these mixed disulfides had to be carried as soon as possible after preparation to avoid artifact formation from the excess ESSE and ES present in the mixture].

B) From cells

Cell pellets were defrosted at room temperature over 5 minutes. Each pellet was re-suspended in $400 \mu \mathrm{L}$ of cold deionised water by briefly aspirating then $2 \times$ $10 \mu \mathrm{l}$ aliquots were taken for cell counting using a C-Chip ${ }^{\circledR}$ disposable haemocytometer. $350 \mu \mathrm{l}$ of the cell suspension was transferred to a $1.5 \mathrm{ml}$ micro-centrifuge tube. Blanks were prepared using $350 \mu \mathrm{l}$ deionised water in place of cell suspension. $50 \mu \mathrm{l}$ of internal standard solution was added to each tube followed by 400 $\mu \mathrm{l} 5 \mathrm{mM}$ ESSE solution (in $0.4 \mathrm{mM}$ phosphate buffer, $\mathrm{pH}$ 7.6). Tubes were vortexed briefly to mix the contents. The cells were lysed on ice using a sonic probe (SoniPrep) on full power for 5 cycles of 10 seconds at an interval of 10 seconds. After vortexing for 15 seconds the tubes were returned to ice for 5 minutes. 200 $\mu \mathrm{l}$ of $50 \% \mathrm{w} / \mathrm{v}$ TCA were added followed by vortexing for 10 seconds. The mixture was then centrifuged at $14,000 \mathrm{rpm}$ at $4^{\circ} \mathrm{C}$ for 20 minutes and the supernatant transferred to LC vials and placed in a cooled auto sampler $\left(+4^{\circ} \mathrm{C}\right)$ prior 
to injection.

\subsection{Ultra-High Performance Liquid Chromatography Analysis}

Gradient UHPLC was performed on an integrated Agilent 1290 UHPLC system, using a TITAN ${ }^{\text {tm }}$ C18 column $(1.8 \mu \mathrm{m}, 100 \mathrm{~mm} \times 2.1 \mathrm{~mm}$ ), (Supelco, Sigma Aldrich.) The flow rate was $0.7 \mathrm{ml} / \mathrm{min}$ and the injection volume was $1 \mu \mathrm{L}$. A post injection needle wash was included in the method to rinse for 3 seconds with $\mathrm{MeOH}$. Column temperature was automatically regulated at $35^{\circ} \mathrm{C}$. Mobile phase A consisted of $0.1 \% \mathrm{v} / \mathrm{v}$ formic acid (HCOOH) in $18.2 \mathrm{~m} \Omega-\mathrm{cm}^{2}$ water. Mobile phase $\mathrm{B}$ was $0.1 \% \mathrm{v} / \mathrm{v}$ formic acid in LC MS grade methanol. The gradient elution profile of 0 mins, $0 \%$ B; 6 mins, $2 \%$ B; 15 mins, $20 \%$ B; 18 mins, $90 \%$ B; 20 mins, $90 \%$ B; 22 mins, $0 \%$ B. The post time was 5 minutes at $0 \% \mathrm{~B}$ was used.

Primary detection and quantification of RSSE components by UV was performed at $325 \mathrm{~nm}$ using a semi micro flow-cell. Details of this method are given as supplementary information.

The UV absorbing peaks detected were examined by mass spectrometry using an Agilent 6540 UHD QToF-MS operating in negative mode with Agilent Dual Jet Stream (ASJ) electrospray ionisation (ESI). The system was programmed to scan the mass range from 50 to 1700 with a scan rate of 3 spectra per second. The source parameters were as follows: Gas Temperature, $250^{\circ} \mathrm{C}$; Gas Flow, 8 1/min; Nebulizer Pressure, 25 psig; Sheath Gas Temperature, $325^{\circ} \mathrm{C}$; Sheath Gas Flow, $10 \mathrm{l} / \mathrm{min}$. During analysis of thiol derivatives only, the collision cell energy was set to 10 and the fragmentation was set to $50.0 \mathrm{~V}$. Mass accuracy was maintained during the run by infusion of mass calibration ions.

LC-MS operation was managed, and data collected, using Agilent Masshunter Acquisition Software B. 06. MS data was processed and analysed by Agilent Masshunter Qualitative Analysis Software B. 06. Significance testing and foldchange analysis of the data was performed using Mass Profiler Pro (Agilent Technologies, Delaware, USA).

A synopsis of the development of the MS compatible LC methodology is given in the supplementary information.

\subsection{Semi Scaled Preparative HPLC}

This was carried out on an integrated Agilent 1290 UHPLC system. ACE C1Co8 $(250 \times 10 \mathrm{~mm}, 5 \mu \mathrm{M})$. Column Temperature: Ambient $\left(18^{\circ} \mathrm{C}\right)$. Mobile Phase: (A): $0.1 \% \mathrm{HCOOH}$ in $\mathrm{H} 20$, (B): $0.1 \% \mathrm{HCOOH}$ in $\mathrm{MeOH}$. Flow Rate: 8.00 $\mathrm{ml} / \mathrm{min}$. Gradient: 0 min 10\% B; $11.88 \mathrm{~min} 50 \%$ B; $14.77 \mathrm{~min} 90 \%$ B; $17.72 \mathrm{~min}$ 90\% B; 20.68 min 10\% B; 23.63 min 10\% B. Post-time: 10 min. UV: 325 nm.

After repeated injections the pooled sample peaks were freeze dried and resuspended in $100 \% \mathrm{D}_{2} \mathrm{O}$ for NMR analysis.

\subsection{NMR Spectroscopy}

1H NMR data were recorded on a Bruker AVANCE III NMR spectrometer at $500.13 \mathrm{MHz}$ at $300 \mathrm{~K}$ by using a 5 -mm BBI probe equipped with a z-gradient 
coil.

A relaxation delay, $2.4 \mathrm{~s}$; acquisition time, $1.6 \mathrm{~s}$; spectral window $10000 \mathrm{~Hz}, 32$ 768 data points and a number of 128 scans were used to collect the data. A 0.5 $\mathrm{Hz}$ line broadening procedure was applied before Fourier transformation, and baseline correction was performed before integration with Bruker software. The methanol signal was used as an internal reference for chemical shift (3.3 ppm).

The signal from residual water was used as an internal reference for chemical shift (4.7 ppm).

\section{Results}

\subsection{Quantification of Thiols Derivatives in LNCaP by UHPLC-UV}

Implementation of a $10 \mathrm{~cm} \times 2.1 \mathrm{~mm}, 1.8$ um TITAN UHPLC column and subsequent modification of the gradient resulted in resolution of all standard thiol derivatives in addition to two ES related molecules. These latter molecules were noted to be presented upon derivatisation and injection of both individual and mixed standards, suggesting that they were the ES side products of the derivatization.

UV analysis of the RSSE's obtained from the LCNaP ASF in this LC system revealed, in addition to the presence of cysteine, cysteinylglycine and GSH at 4, 6.5 and 10.2 min respectively, an unidentified minor component eluting at 11.4 min as shown in Figure 2.

The concentration of each known thiol species present in the ASF was calculated using external calibration plots after validation of the UHPLC-UV methodology (see supplementary information for method validation) and is presented in Table 1.

Thus the total concentration of the identified thiols (RSSE) was estimated to be 11.84 femtomoles per cell, which matches closely the value of 13.10 femtomoles per cell obtained using the traditional Ellman assay by UV spectrophotometry. It is possible that the remainder of the thiols do not react with the Ellman reagent to produce a mixed disulfide (unpublished data). The concentration of the unknown was estimated using an average extinction coefficient obtained from the known RSSE's.

\subsection{Identification of the Unknown by MS and NMR}

\subsubsection{Mass Spectrometry Analysis}

Hyphenated MS analysis was carried out and an accurate mass of $m / z 405.0058$ was obtained for the unknown minor component. An empirical formula $\mathrm{C}_{13} \mathrm{H}_{14} \mathrm{~N}_{2} \mathrm{O}_{9} \mathrm{~S}_{2}$ with an associated mass error of $-0.01 \mathrm{ppm}$ was derived for the thiol derivative in its neutral form. After addition of two protons to account for the disulphide bond formation and negative ionisation, the molecular formula for the unknown thiol in its native form (not derivatized) was deducted to be $\mathrm{C}_{6} \mathrm{H}_{11} \mathrm{NO}_{5} \mathrm{~S}$ with a molecular weight of 209 . However, the structure of this metabolite could not be identified by comparison with mass spectral databases.

In order to ascertain the thiol nature of this component and to obtain further 


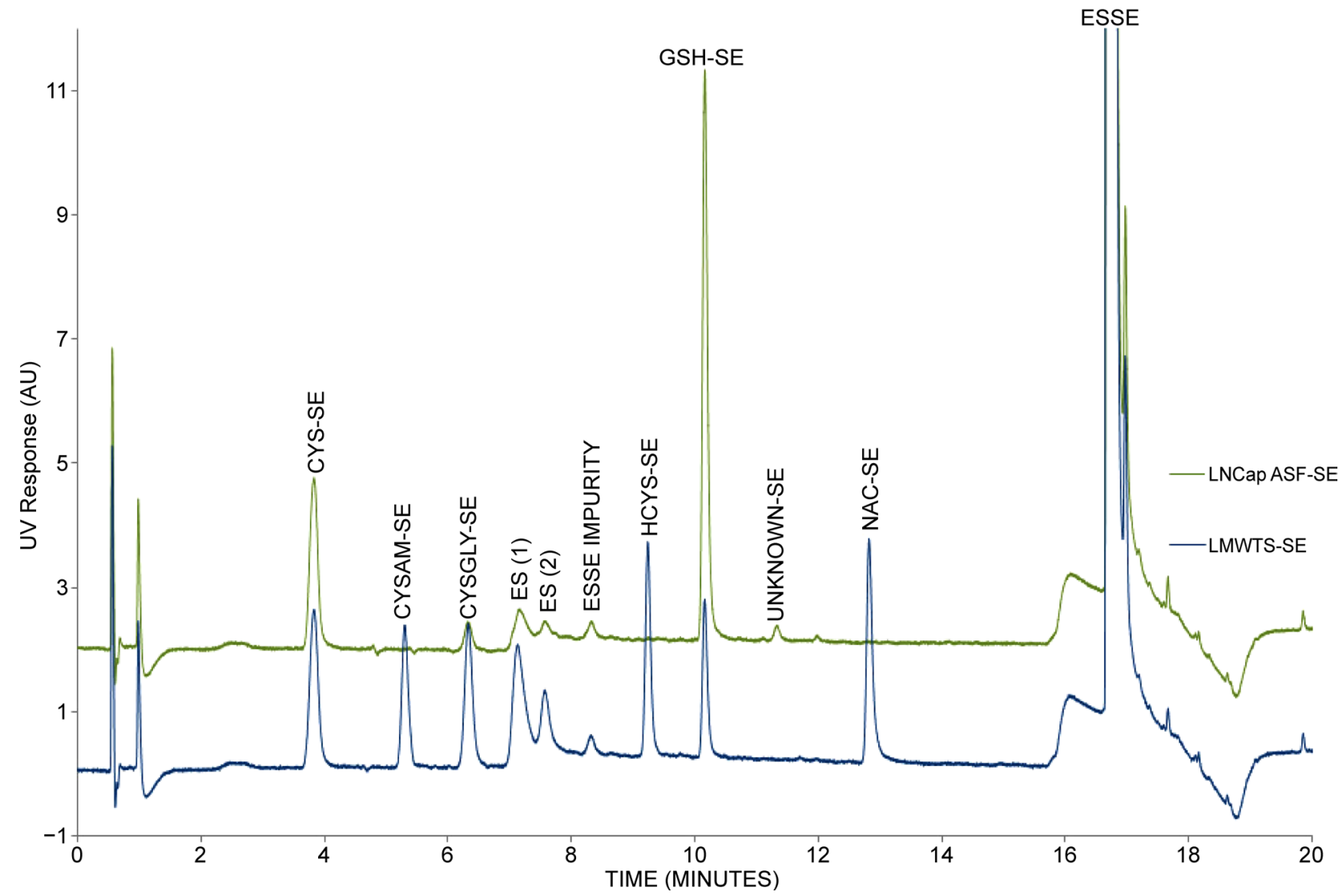

Figure 2. UHPLC-UV chromatograms of standard RSSE derivatives (lower blue trace) and in the ASF of LNCaP cells (upper green trace). Column: SUPELCO TITAN-C18 $100 \times 2.1 \mathrm{~mm}, 1.8 \mu \mathrm{M}$; Mobile Phase: (A) $\mathrm{H}_{2} \mathrm{O} 0.1 \%$ v/v HCOOH, (B) MeCN 0.1\% v/v HCOOH; Injection Volume: $1 \mu \mathrm{L}$; Temperature: $35^{\circ} \mathrm{C}$; Flow Rate: $0.7 \mathrm{ml} / \mathrm{min}$; Gradient: $0 \mathrm{~min}, 100 \% \mathrm{~A} ; 6 \mathrm{~min}, 98 \% \mathrm{~A} ; 15$ $\min , 80 \%$ A; $18 \mathrm{~min}, 100 \%$ A; $20 \mathrm{~min}, 10 \%$ A; $22 \mathrm{~min}, 100 \%$ A; Post Time: $5 \mathrm{~min}$; UV: $325 \mathrm{~nm}$.

Table 1. UHPLC quantitation of LNCaP cell RSSE components.

\begin{tabular}{lc}
\hline \multicolumn{1}{c}{ RSSE components } & Concentration in femtomoles per cell \\
\hline Acid soluble fraction (ASF): total thiol content (Ellman assay) & $13.10 \pm 0.80$ \\
GS-SE glutathione & $8.30 \pm 0.73$ \\
CYS-SE cysteine & $2.70 \pm 0.04$ \\
CYSGLY-SE cysteinylglycine & $0.83 \pm 0.10$ \\
Unknown S-SE & 0.011 (estimate) \\
\hline
\end{tabular}

structural information, the fragmentation pattern of standard thiols derivatives was investigated by tandem mass spectrometry.

MS/MS fragmentation of all standard thiol derivatives (including the Ellman reagent itself) systematically led to the generation of an ES fragment $\mathrm{m} / \mathrm{z} 197.9867$ (see supplementary information). This is illustrated in Figure 3 showing the UV trace and the extracted ion chromatogram (EIC) of the $\mathrm{m} / \mathrm{z} 197.9867$ ion (theoretical exact mass), obtained in negative ion mode

This method was therefore used to investigate the fragmentation pattern of the unknown analyte in the LNCaP cellular extract detected by UV analysis. The MS/MS spectrum obtained is presented in Figure 4. 


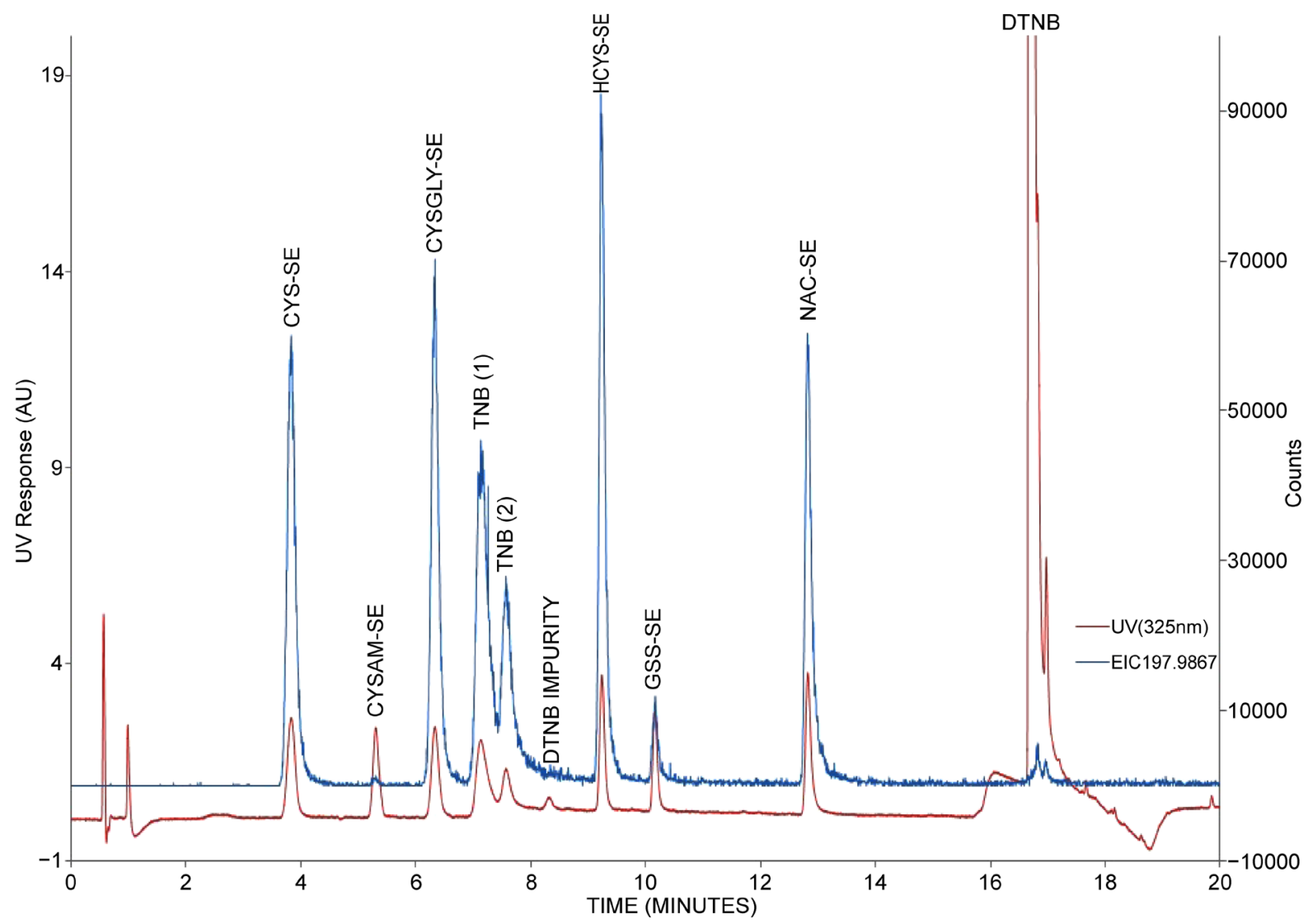

Figure 3. Chromatographic traces-UV (red trace) and EIC 197.9867 (blue trace) showing the pattern obtained from standard mixed thiol derivatives. Column: SUPELCO TITAN-C18 $100 \times 2.1 \mathrm{~mm}, 1.8 \mu \mathrm{M}$; Mobile Phase: (A) $\mathrm{H}_{2} \mathrm{O} 0.1 \% \mathrm{v} / \mathrm{v} \mathrm{HCOOH}$, (B) $\mathrm{MeCN}$ 0.1\% v/v HCOOH; Injection Volume: $1 \mu \mathrm{L}$; Temperature: $35^{\circ} \mathrm{C}$; Flow Rate: $0.7 \mathrm{ml} / \mathrm{min}$; Gradient: 0 min, $100 \%$ A; 6 min, 98\% A; $15 \mathrm{~min}, 80 \%$ A; $18 \mathrm{~min}, 100 \%$ A; $20 \mathrm{~min}, 10 \%$ A; $22 \mathrm{~min}, 100 \%$ A; Post Time: 5 min; UV: 325 nm; MS Mode: Negative; Scan $50-1700 \mathrm{~m} / \mathrm{z}$ (EIC for 197.9867).

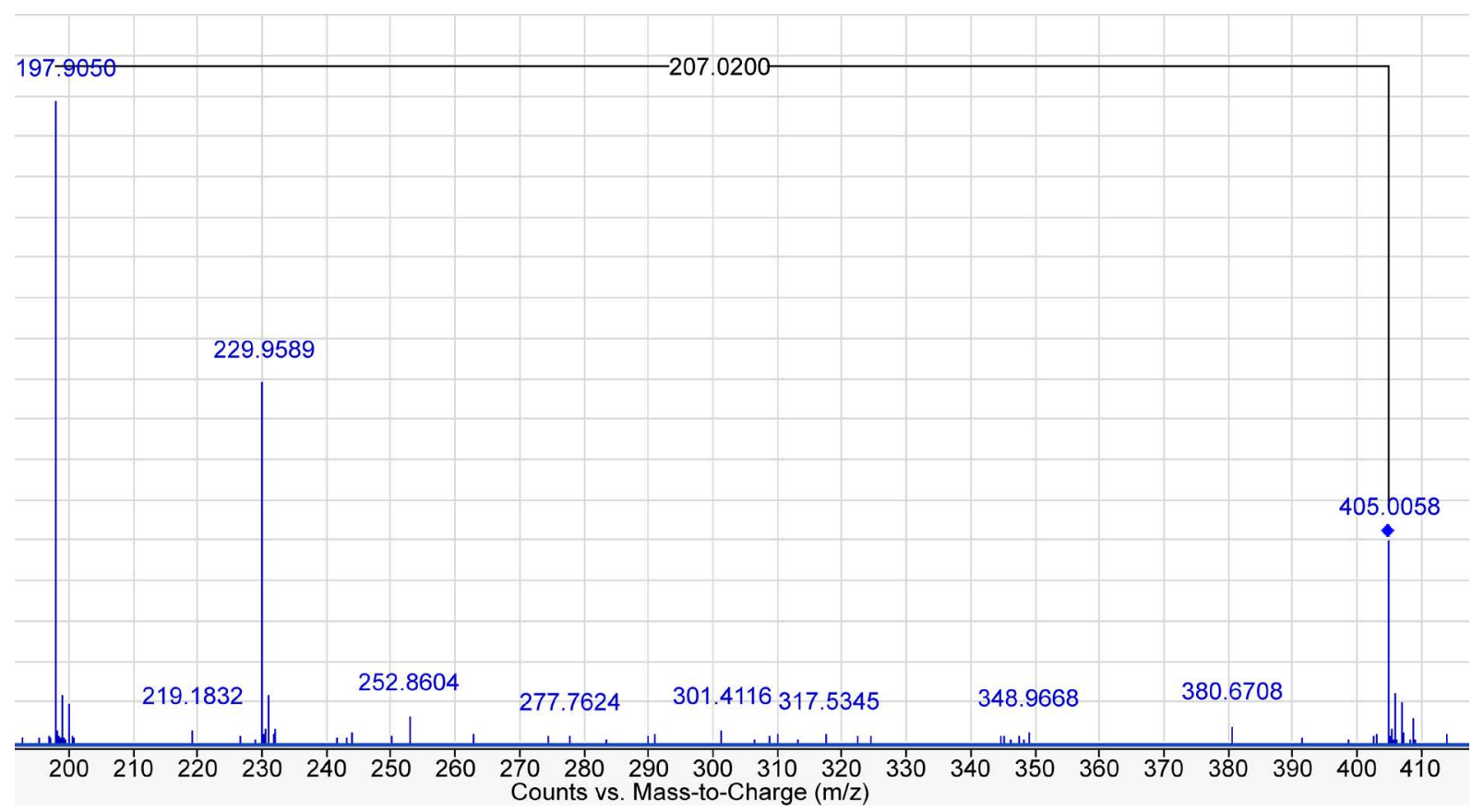

Figure 4. MS fragmentation spectrum of the unknown derivative. 
Two fragments were observed at 229.9589 and $197.9858 \mathrm{~m} / z$, the former being identified as the ES-S ${ }^{-}$ion whereas the latter, corresponding to the ES ion, confirmed the thiol nature of the analyte (Table 2).

However, even in conjunction with the number of double bond equivalents in $\mathrm{C}_{6} \mathrm{H}_{11} \mathrm{NO}_{5} \mathrm{~S}$ determined to be 2 , the structure of the unknown thiol could not be identified by MS or MS/MS alone. Therefore sufficient material for an NMR analysis had to be generated using preparative chromatography.

\subsubsection{Identification of the Isolated Unknown by NMR Spectroscopy}

Derivatized cellular extracts from LNCaP were injected onto a semi-preparative column as illustrated in Figure 5.

Table 2. Measured $m / z$ and MFG results for the unknown derivative.

\begin{tabular}{cccc}
\hline Ion species & Measured $\mathbf{m} / \boldsymbol{z}$ & Molecular formula (MFG) [M] & Difference (ppm) \\
\hline Unknown-SE $[\mathrm{M}-\mathrm{H}]^{-}$ & 405.0058 & $\mathrm{C}_{13} \mathrm{H}_{14} \mathrm{~N}_{2} \mathrm{O}_{9} \mathrm{~S}_{2}$ & 2.4 \\
{$[\mathrm{ES}]^{-}$} & 197.9858 & $\mathrm{C}_{7} \mathrm{H}_{5} \mathrm{NO}_{4} \mathrm{~S}$ & 4.3 \\
{$[\mathrm{ES}-\mathrm{S}]^{-}$} & $\mathbf{2 2 9 . 9 5 8 9}$ & $\mathrm{C}_{7} \mathrm{H}_{5} \mathrm{NO}_{4} \mathrm{~S}_{2}$ & $\mathbf{0 . 7 7}$ \\
\hline
\end{tabular}

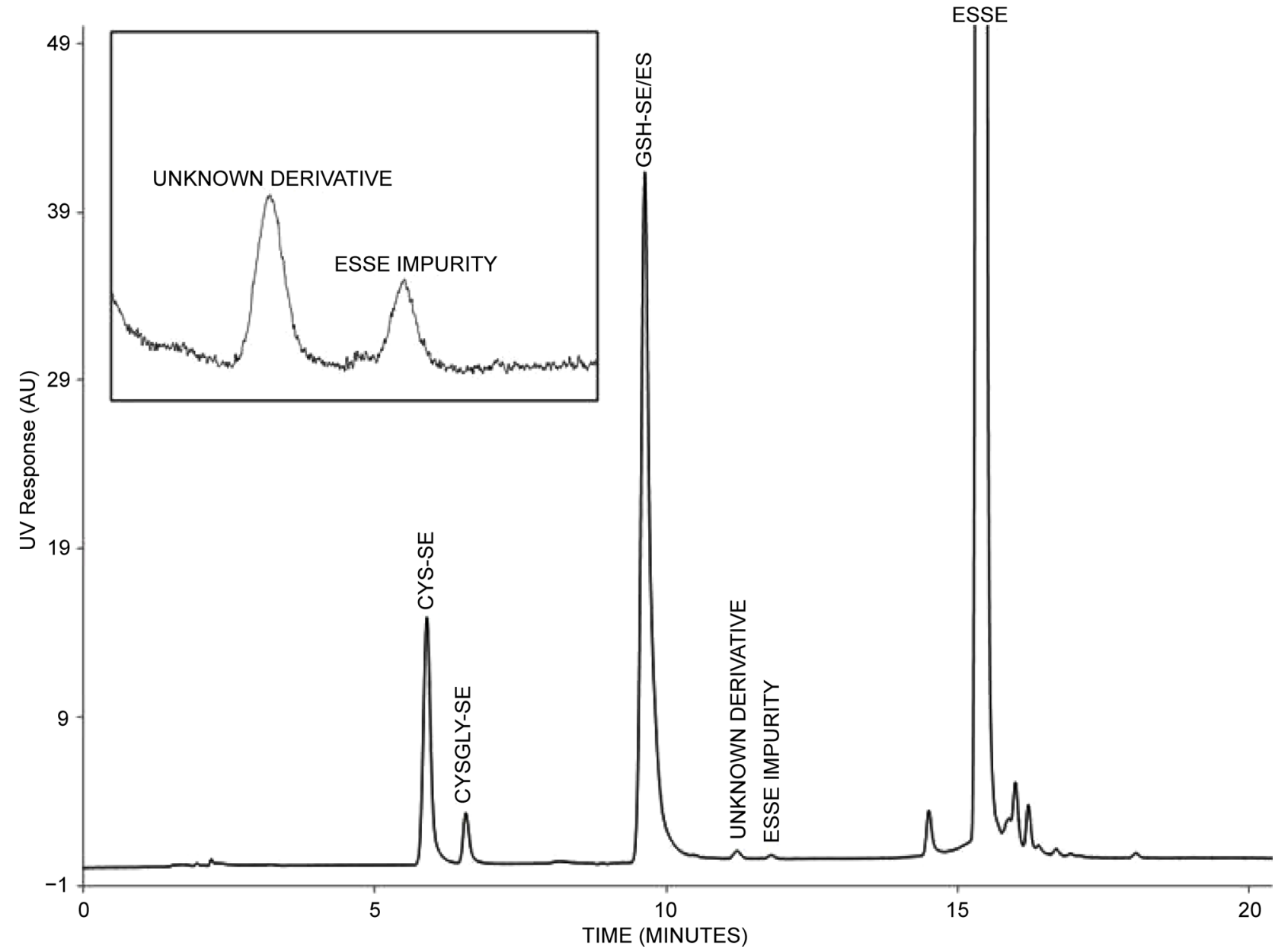

Figure 5. UV chromatogram showing a $900 \mu \mathrm{L}$ injection of ESSE derivatised LNCaP ASF on the semi-preparative scaled method. Inset: expanded region of the chromatogram between 10.5 and $13 \mathrm{~min}$. 
The purified, dried derivative was dissolved in $100 \% \mathrm{D}_{2} \mathrm{O}$ and transferred to an NMR tube for ${ }^{1} \mathrm{H}$ analysis. 1D proton and 2D TOCSY (not shown). Initial spectra were acquired as illustrated in Figure 6.

The proton NMR spectrum revealed the presence of signals integrating for a total of 9 non-exchangeable protons and two ABX systems suggesting the presence of two chiral centres. One of the ABX systems was assigned to a CYS moiety by comparison of the signals and chemical shifts from those of a CYS-SE purified derivative. The second $\mathrm{ABX}$ spin system, which by deduction has a molecular formula $\mathrm{C}_{3} \mathrm{H}_{3} \mathrm{O}_{3}$, is consistent with a glycerate moiety giving signals at 3.72 and $4.07 \mathrm{ppm}$. The signal at $3.65 \mathrm{ppm}$ was excluded from the integration based on spectra obtained by DOSY experiment (data not shown), suggesting that it belonged to a molecule of a different size, hence diffusing at a different rate in solution.

Further mass spectrometry analysis by direct infusion of the isolated derivative molecule dissolved in $\mathrm{D}_{2} \mathrm{O}: \mathrm{CD}_{3} \mathrm{OD}$ [50:50], produced a molecular ion of 409 $\mathrm{m} / \mathrm{z}$ in negative ion mode, suggesting that the neutral molecule contains 5 exchangeable protons. This gives overall 14 protons which is consistent with the empirical formula previously determined. The assignment of the proton NMR signals is given in Table 3. Based on the data obtained, this new thiol metabolite
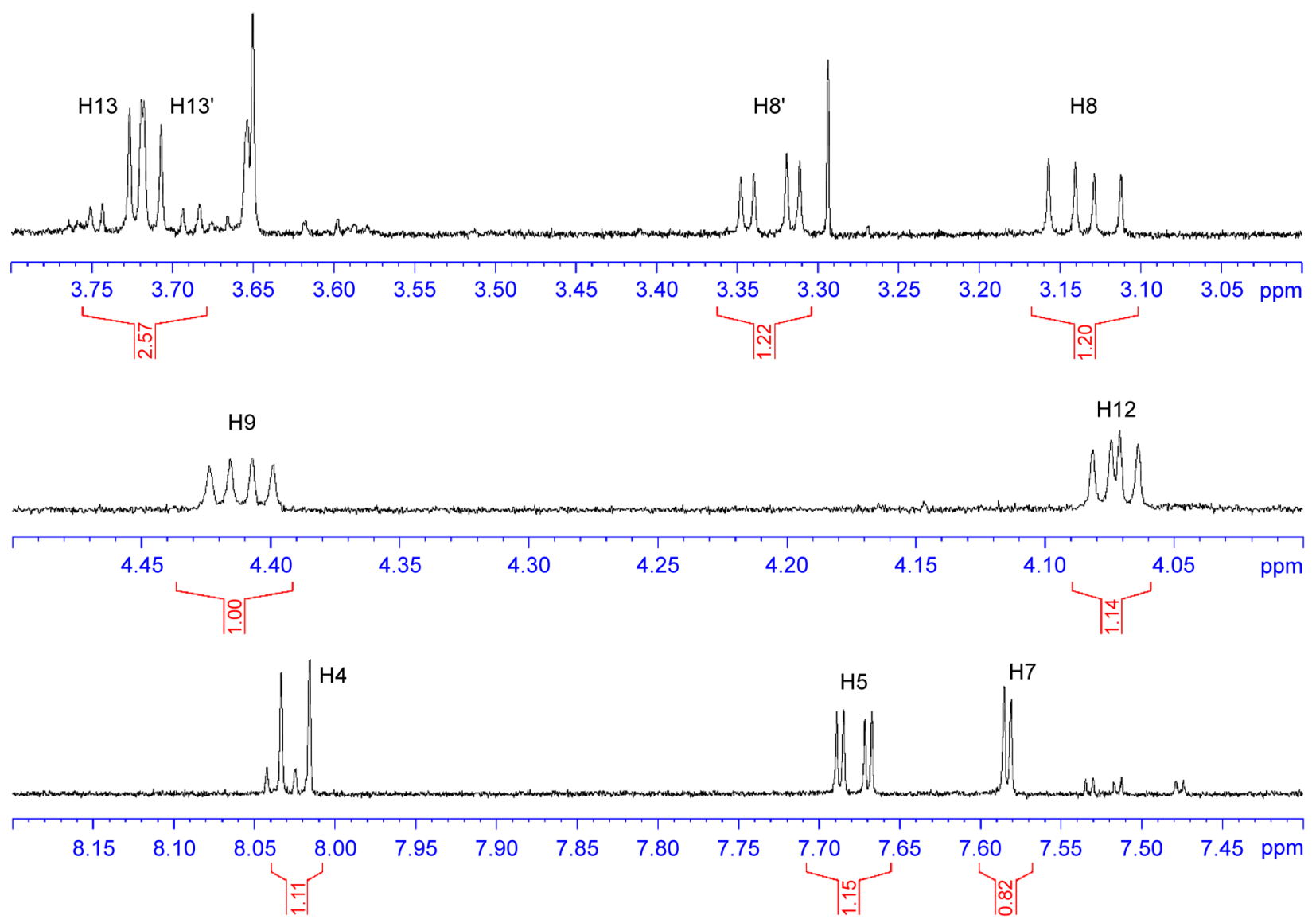

Figure 6. $\delta 8.2$ - 2 ppm expanded regions of the NMR spectrum of unknown derivative obtained with 128 scans (15 min acquisition time). 
was identified as Cysteinylglycerate (CYSGC) as shown in Figure 7. The molecule was suggested to be the $(\mathrm{R}, \mathrm{R})$ diastereoisomer as would be expected naturally.

\section{Discussion}

Cellular thiols are recognised as playing an important role in normal cellular function and redox regulation through antioxidant activity. A major cell thiol, the low molecular weight thiol GSH, is now regarded as an important factor in the cellular defence against oxidative stress. The metabolism of this cysteine containing tripeptide has been studied in detail over the last century (for reviews see [10] [16]), particularly in regard to its important role in the removal of xenobiotics and suspected carcinogens from the cell via the glutathione transferase enzymes [17]. In addition to participating in many physiologically important cell functions it has been shown to play an important role in in the sensitivity of tumors to the cytotoxic effects of anticancer chemotherapeutic drugs [12].

Unfortunately, due to the paucity of reliable analytical methods for GSH estimation the results of many investigations on tumor cells have been variable and difficult to interpret. However, recent improvements in HPLC techniques for the

Table 3. Structure of $(\mathrm{R}, \mathrm{R})$ cysteinyl glycerate derivative with assignment of the proton NMR signals.

\begin{tabular}{ccccc}
\hline $\begin{array}{c}\text { Proton } \\
\text { number }\end{array}$ & $\begin{array}{c}\text { Chemical Shift } \\
(\mathbf{p p m})\end{array}$ & Multiplicity & Coupling constant & Integration \\
\hline H4 & 8.03 & Doublet & ${ }^{3} \mathrm{~J}=8.9 \mathrm{~Hz}$ & 1.11 \\
H5 & 7.67 & Doublet of doublet & ${ }^{3} \mathrm{~J}=8.9 \mathrm{~Hz} ;{ }^{4} \mathrm{~J}=2.2 \mathrm{~Hz}$ & 1.15 \\
H7 & 7.58 & Doublet & ${ }^{4} \mathrm{~J}=2.2 \mathrm{~Hz}$ & 0.82 \\
H8 & 3.1 & Doublet of doublet & ${ }^{2} \mathrm{~J}=14.1 \mathrm{~Hz} ;{ }^{3} \mathrm{~J}=8.35 \mathrm{~Hz}$ & 1.20 \\
H8 & 3.35 & Doublet of doublet & ${ }^{2} \mathrm{~J}=14.1 \mathrm{~Hz} ;{ }^{3} \mathrm{~J}=4.05 \mathrm{~Hz}$ & 1.22 \\
H9 & 4.4 & Doublet of doublet & ${ }^{3} \mathrm{~J}=4.05 \mathrm{~Hz} ;{ }^{3} \mathrm{~J}=8.35 \mathrm{~Hz}$ & 1.00 \\
H12 & 4.1 & Doublet of doublet & ${ }^{3} \mathrm{~J}=3.5 \mathrm{~Hz} ;{ }^{3} \mathrm{~J}=5.2 \mathrm{~Hz}$ & 1.14 \\
H13 & 3.7 & Doublet of doublet & ${ }^{2} \mathrm{~J}=12 \mathrm{~Hz} ;{ }^{3} \mathrm{~J}=3.70 \mathrm{~Hz}$ & \\
H13' & 3.7 & Doublet of doublet & ${ }^{2} \mathrm{~J}=12 \mathrm{~Hz} ;{ }^{3} \mathrm{~J}=5.1 \mathrm{~Hz}$ & 2.57 \\
\hline
\end{tabular}

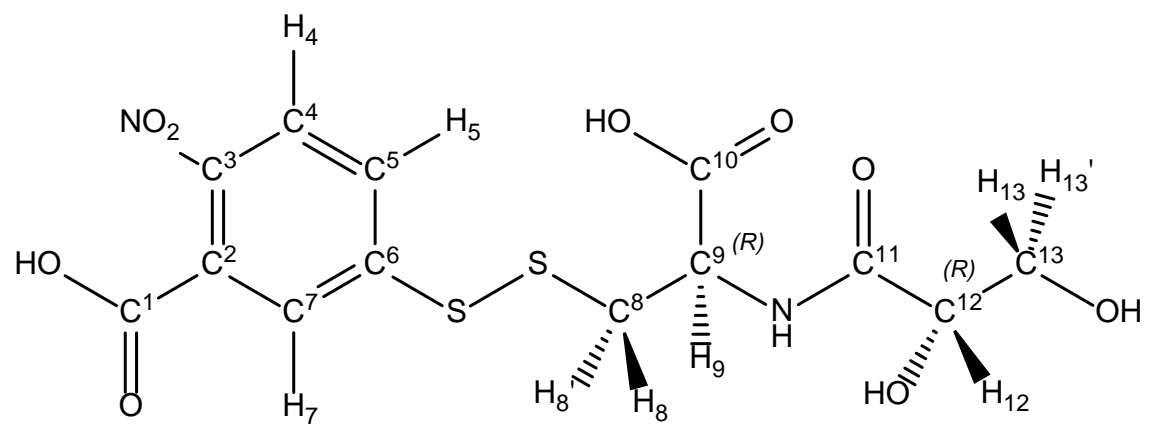

Figure 7. Structure of unknown metabolite. 
estimation of GSH [18] and other thiols, such those illustrated in this paper, should help greatly to elucidate the role of LMWT thiols in tumor metabolism.

The results reported here confirm the previously reported findings of lower percentage GSH content in the acid soluble fraction of LNCaP cells than usually found in other cells [7]. The amount of GSH present in the ASF was higher than previously found; possibly due to 2 hours re-incubation of confluent cells in fresh medium employed before harvesting. However the presence of significant quantities of cysteine (which usually quickly incorporated into GSH) and cysteinylglycine indicates that abnormal/aberrant GSH metabolic pathways exist in this tumor cell line [19]. In the normal cellular synthesis of GSH the only cysteinyl dipeptide involved is $\gamma$-glutamylcysteine; GSH synthetase adds glycine to this to give the tripeptide. Free dipeptide cysteinylglycine is not normally present and if formed it is broken down by a dipeptidase to generate cysteine and glycine. The only enzyme that can hydrolyse GSH, removing the glutamate to give cysteinylglycine, is $\gamma$-glutamyltranspeptidase which is only present on the external surfaces of certain cell types [20].

Whether this pattern of low molecular weight thiols is a characteristic of lymph node metastatic cells in general is yet to be ascertained. However, in a study of human prostate cells obtained from clinical biopsy samples Chaiswing et al. [21] demonstrated a decrease in GSH (using an enzyme assay) and an increase in cysteine levels in these samples with increasing Gleason scores (a clinical measure of an increased presence of malignant cells). They attributed this to redox imbalance occurring with prostate cancer progression. They concluded that, as treatment of metastatic cancer is generally unsuccessful, further knowledge of redox-state profiles in these cancers may help to predict their behaviour and response to chemotherapeutic drugs and radiation.

The presence of a new metabolite, cysteinylglycerate, albeit in small quantities, may be due to a defect in the usual phosphoglycerate pathways; phosphoglycerates are important biochemical intermediates in glycolysis. Increased glycolysis is a feature of the well-known Warburg effect of increased anaerobic respiration found in most tumour cells [22] though there have been no reports of glycerate being involved with thiol metabolism.

Cysteinylglycerate might prove to be a useful biomarker for this kind of tumour, however further metabolomic investigations are needed to establish the biochemical relevance of this new metabolite in the overall biochemistry of lymph node metastatic cells and to evaluate its diagnostic potential.

\section{Conclusion}

Using the Ellman reagent as a label for the LMWT present in LNCaP metastatic tumor cells, we have identified 4 components. In ascending order of concentration, they are glutathione, cysteine, cysteinylglycine and cysteinylglycerate. Further, metabolomic investigations are needed to establish their importance in the overall biochemistry of lymph node metastatic cell. This knowledge may aid the development of new chemotherapeutic agents to treat metastatic tumours that 
are resistant to radiation and cannot be effectively removed by surgery.

\section{Acknowledgements}

The authors wish to thank the Cambridge Cancer Research Fund for generous financial support throughout this project.

\section{References}

[1] (2013) NCI Statistics. https://seer.cancer.gov/statfacts/html/prost.html

[2] Cancer Research UK. Org Prostate Cancer Statistics. 2012. http://info.cancerresearchuk.org/cancerstats/types/prostate/incidence/\#geog

[3] Gupta-Elera, G., Garrett, A.R., Robison, R.A. and O’Neill, K.L. (2012) The Role of Oxidative Stress in Prostate Cancer. European Journal of Cancer Prevention, 21, 155-162. https://doi.org/10.1097/CEJ.0b013e32834a8002

[4] Paschos, A., Pandya, R., Duivenvoorden, W.C.M. and Pinthus, J.H. (2013) Oxidative Stress in Prostate Cancer: Changing Research Concepts towards a Novel Paradigm for Prevention ad Therapeutics. Prostate Cancer and Prostatic Disease, 16, 217-225. https://doi.org/10.1038/pcan.2013.13

[5] Haugarrd, N. (2000) Reflections on the Role of the Thiol Group in Biology. Annals of the New York Academy of Sciences, 899, 148-158. https://doi.org/10.1111/j.1749-6632.2000.tb06183.x

[6] Harris, C. and Hansen, J.M. (2012) Oxidative Stress, Thiols, and Redox Profiles. Methods in Molecular Biology, 889, 325-346.

https://doi.org/10.1007/978-1-61779-867-2 21

[7] Bindoli, A., Fukuto, J.M. and Forman, H.J. (2008) Thiol Chemistry in Peroxidase Catalysis and Redox Signaling. Antioxidants \& Redox Signaling, 10, 1549-1564.

[8] Chaiswing, L., Zhong, W. and Oberley, T.D. (2011) Distinct Redox Profiles of Selected Human Prostate Carcinoma Cell Lines: Implications for Rational Design of Redox Therapy. Cancers, 3, 3557-3584. https://doi.org/10.3390/cancers3033557

[9] Chaiswing, L., Zhong, W., Liang, Y., Jones, D.P. and Oberley, T.D. (2012) Regulation of Prostate Cancer Cell Invasion by Modulation of Extra- and Intracellular Redox Balance. Free Radical Biology \& Medicine, 52, 452-461. https://doi.org/10.1016/j.freeradbiomed.2011.10.489

[10] Dickinson, D.A. and Forman, H.J. (2002) Cellular Glutathione and Thiols Metabolism. Biochemical Pharmacology, 64, 1019-1026. https://doi.org/10.1016/S0006-2952(02)01172-3

[11] Forman, H.J., Zhang, H. and Rinna, A. (2009) Glutathione: Overview of Its Protective Roles, Measurement and Biosynthesis. Molecular Aspects of Medicine, 30, 1-12. https://doi.org/10.1016/j.mam.2008.08.006

[12] Traverso, N., Ricciari, R., Nitti, M., Marengo, B., Furfaro, A.L., Pronzato, M., Marinari, U.M. and Domenicotti, C. (2013) Role of Glutathione in Cancer Progression and Chemoresistance. Oxidative Medicine and Cellular Longevity, 2013, Article ID: 972913. https://doi.org/10.1155/2013/972913

[13] Gronow, M. (2010) Studies on the Non-Protein Thiols of a Human Prostatic Cancer Cell Line: Glutathione Content. Cancers, 2, 1092-1106. https://doi.org/10.3390/cancers2021092

[14] Ellman, G.L. (1959) Tissue Sulfhydryl Groups. Archives of Biochemistry and Biophysics, 82, 70-77. https://doi.org/10.1016/0003-9861(59)90090-6 
[15] Russell, J., McKeown, J.A., Hensman, C., Smith, W.E. and Reglinski, J. (1997) HPLC Determination of Biologically Active Thiols Using Pre-Column Derivatization with 5,5'-Dithio-(Bis-2-Nitrobenzoic Acid). Journal of Pharmaceutical and Biomedical Analysis, 15, 1757-1763. https://doi.org/10.1016/S0731-7085(96)02019-5

[16] Vina, J. (1990) Glutathione: Metabolism and Physiological Functions. CRC Press, Boca Raton.

[17] Hayes, J.D. and Pulford, D.J. (1995) The Glut Athione S-Transferase Supergene Family: Regulation of GST and the Contribution of the Lsoenzymes to Cancer Chemoprotection and Drug Resistance Part I. Critical Reviews in Biochemistry and Molecular Biology, 30, 445-599. https://doi.org/10.3109/10409239509083491

[18] Monostori, P., Wittmann, G., Karg, E. and Turi, S. (2009) Determination of Glutathione and Glutathione Disulfide in Biological Samples: An In-Depth Review. Journal of Chromatography B, 877, 3331-3346. https://doi.org/10.1016/j.jchromb.2009.06.016

[19] Childs, S., Haroune, N., Wlliams, L. and Gronow, M. (2016) Determination of Cellular Glutathione: Glutathione Disulfide Ratio in Prostate Cancer Cells by High Performance Liquid Chromatography with Electrochemical Detection. Journal of Chromatography A, 1437, 67-73. https://doi.org/10.1016/j.chroma.2016.01.050

[20] Lu, S.C. (2013) Glutathione Biosynthesis. Biochimica et Biophysica Acta (BBA)General Subjects, 1830, 3143-3153. https://doi.org/10.1016/j.bbagen.2012.09.008

[21] Chaiswing, L., Zhong, W. and Oberley, T.D. (2014) Increasing Discordant Antioxidant Protein Levels and Enzymatic Activities Contribute to Increasing Redox Imbalance Observed during Human Prostate Cancer Progression. Free Radical Biology and Medicine, 67, 342-352. https://doi.org/10.1016/j.freeradbiomed.2013.11.006

[22] Chen, Z., Qian, Y. and Wu, S. (2015) The Warburg Effect: Evolving Interpretations of an Established Concept. Free Radical Biology and Medicine, 79, 253-263. https://doi.org/10.1016/j.freeradbiomed.2014.08.027 


\section{Supplementary Information}

\subsection{Method Validation for UV Quantification}

The achieved chromatographic resolution of derivatised thiol standards and the use of a specific wavelength for derivative moieties ensured the suitable selectivity of this method for analysis of LNCaP cellular thiols.

\subsection{Determination of Lower Limits of Detection}

The lower limits of detection were established for each derivative standard by sequentially reducing the concentration of standard thiol injected onto the column until a signal to noise ratio (S:N) of 3:1 was observed. Triplicate injections at the LLOD concentration were performed to confirm these values. The LLOD was determined to be $2.1 \mu \mathrm{M}$ for CYS-SE, $1.6 \mu \mathrm{M}$ for GS-SE and $2.7 \mu \mathrm{M}$ for CYSGLY-SE

\subsection{Determination of Lower Limits of Quantitation (LLOQ) \& Intraday Precision}

The lower limits of quantitation and intraday precision were assessed simultaneously by measuring 8 repeat injections at the concentration deemed to be the lower limit of quantitation. This concentration gave a peak area response with a coefficient of variation less than 3\% for the derivatised standards and therefore is a suitable LLOQ as illustrated in Table S1.

\subsection{Determination of Interday Precision}

Interday precision was assessed to ascertain the stability of the method over an extended period of time with respect to the peak response and retention time of the thiol derivatives in the sample. Freshly prepared derivatised LNCaP cellular extract was injected six times over six consecutive days and was stored at ambient temperature in the autosampler between days. The coefficient of variation was determined for each derivative analyte over the course of the validation as shown in Table S2.

The coefficients of variation for retention time and peak area of the analytes are shown to be less than $10 \%$ and therefore are within the criteria limits for biological method validation.

\subsection{Determination of Linearity}

Linearity was assessed for each standard derivative by injecting a mixed standard

Table S1. LLOQ \& intraday precision results.

\begin{tabular}{cccc}
\hline & CYS-SE & GS-SE & CYSGLY-SE \\
\hline Concentration (mM) & 0.0083 & 0.0066 & 0.0053 \\
Mean Peak Area (mAu) & 4.04 & 3.94 & 2.24 \\
S.D. & 0.048 & 0.070 & 0.048 \\
\%RSD & 1.199 & 1.768 & 2.164 \\
\hline
\end{tabular}


over a range of concentrations span from the LLOQ to a concentration at which the response is no longer deemed to be linear, indicated by a decrease in the $\mathrm{R}^{2}$ value of the trend line. The linear ranges determined demonstrate high $\mathrm{R}^{2}$ values, indicating the high accuracy of this method. The linearity assay conforms to the FDA standard of a minimum of five data points across the linear range as illustrated in Table S3.

\subsection{Mass Spectrometry Analysis}

\section{a) Negative ion mode MS Analysis}

Analysing the RSSE thiol derivatives standards by MS in negative mode systematically yielded a fragment at $197.9873 \mathrm{~m} / \mathrm{z}$ through in source fragmentation. Example MS spectra obtained with GSH-SE and an ES related impurity generated during the derivatisation process are shown in Figure S1. The proposed structure of the ES related impurity matched the observed mass with a ppm difference of 3.03. This indicates a very close agreement.

Further MS/MS studies showed that the 197.9873 fragment arose specifically from the RSSE derivatives. In order to elucidate the unknown thiol the process of determining the molecular formula was investigated initially using the glutathione derivative. Using the observed mass difference between the derivative molecular ion and the TNB fragment provided the accurate mass of the thiol molecule, absent a proton from ionisation and another from cleavage of the disulphide bond (Figure S2).

Molecular formula generation was also used to confirm the protocol had identified the correct fragment by comparing with the known molecular formula as shown in Table S4.

Following the rationale that the unknown molecule fragments similarly GS-SE as shown in the previous figure, the molecular formula of the un-derivatised molecule was calculated by measurement of the mass difference and calculation of the best fitting molecular formula as shown in Figure S3 and Table S5.

Table S2. Interday precision results.

\begin{tabular}{ccccccc}
\hline & \multicolumn{3}{c}{ Peak Areak (mAu) } & \multicolumn{2}{c}{ Retention Time (minutes) } \\
\cline { 2 - 6 } & $C Y S-S E$ & $G S-S E$ & CYSGLY-SE & $C Y S-S E$ & $G S-S E$ & $C Y S G L Y-S E$ \\
\hline Mean & 47.29 & 36.69 & 87.63 & 1.17 & 2.92 & 3.95 \\
S.D. & 1.666 & 2.407 & 2.185 & 0.054 & 0.075 & 0.071 \\
\%RSD & 3.523 & 6.560 & 2.494 & 4.596 & 2.551 & 1.811 \\
\hline
\end{tabular}

Table S3. Linearity results for derivative standards.

\begin{tabular}{cccc}
\hline & \multicolumn{3}{c}{ Concentration (mM) } \\
\cline { 2 - 4 } Linear Range & $C Y S-S E$ & $G S-S E$ & $C Y S G L Y-S E$ \\
\hline LLOQ & 0.0083 & 0.0066 & 0.0053 \\
ULOQ & 1.0657 & 0.8422 & 0.6785 \\
$\mathbf{R}^{2}$ & 1 & 0.999 & 1 \\
\hline
\end{tabular}



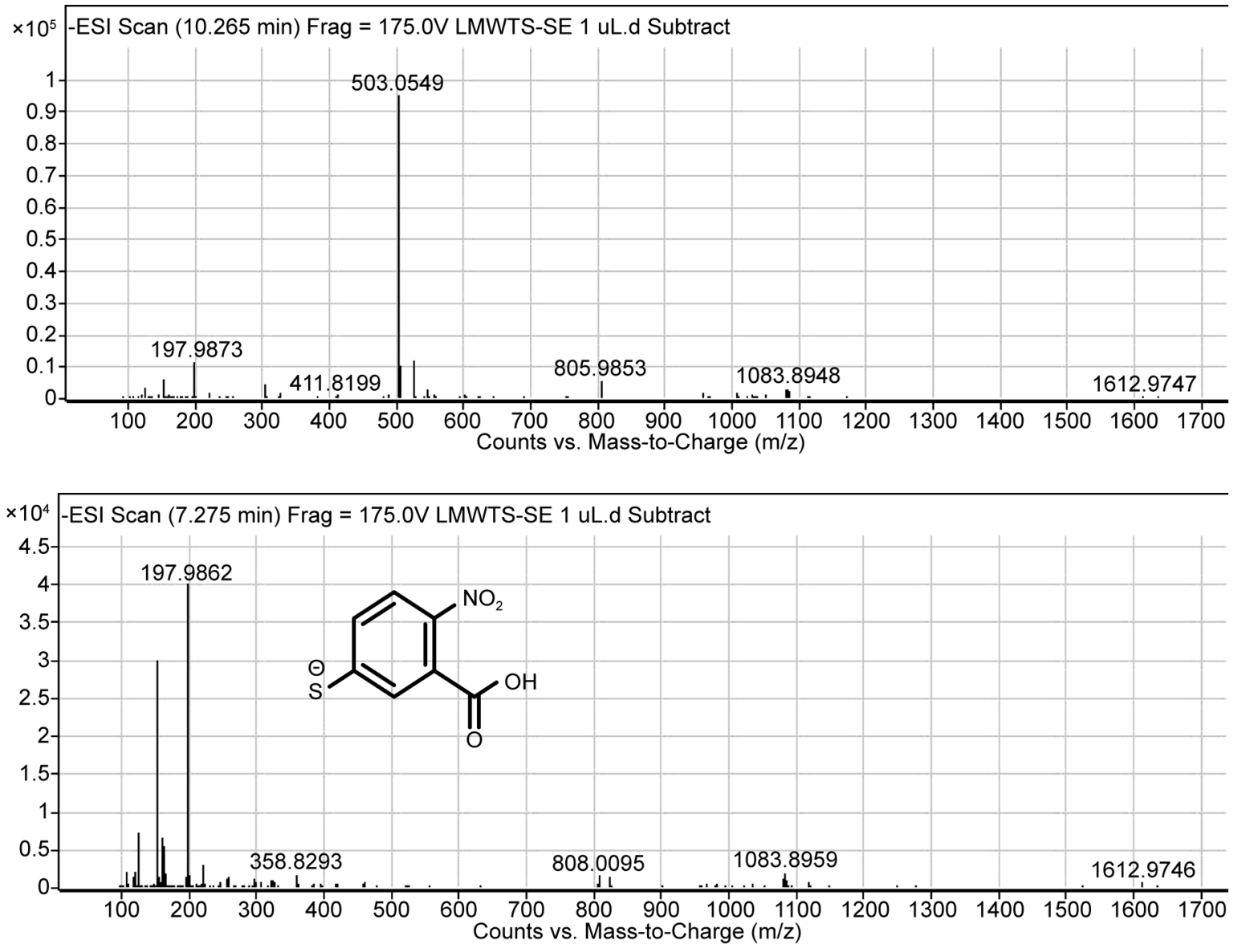

Figure S1. MS spectra of GSSE (top) and ES peak (bottom), with proposed fragment structure (inset).

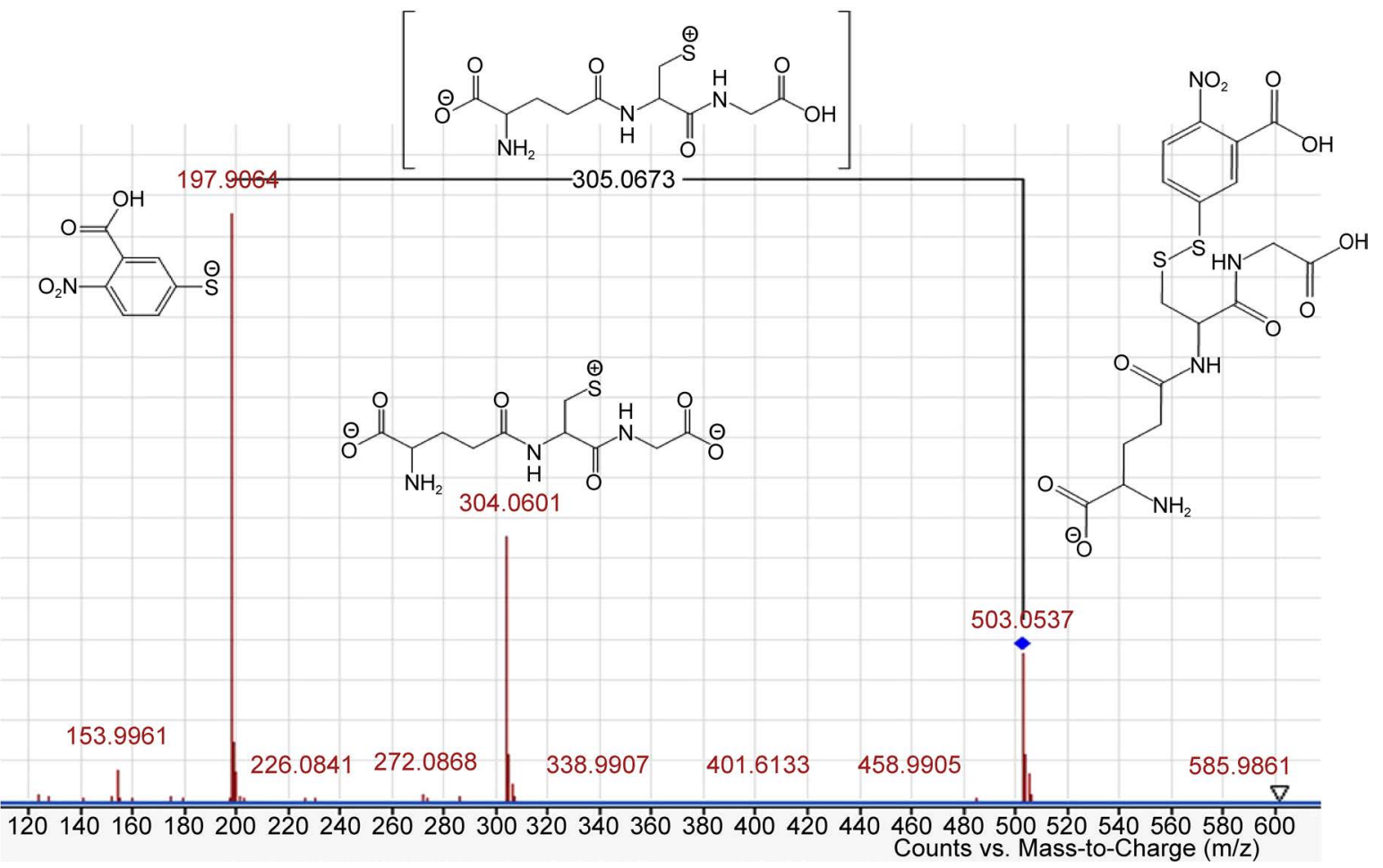

Figure S2. Negative mode fragmentation spectrum of GS-SE. 
Table S4. Measured $m / z$ and MFG results for GS-SE.

\begin{tabular}{|c|c|c|c|c|}
\hline Ion Species & Measured $m / z[\mathrm{M}-\mathrm{H}]^{-}$ & Molecular Formula (MFG) $[\mathrm{M}]$ & Difference (ppm) & Molecular Formula (Known) $[\mathrm{M}]$ \\
\hline GS-SE & 503.0537 & $\mathrm{C}_{17} \mathrm{H}_{20} \mathrm{~N}_{4} \mathrm{O}_{10} \mathrm{~S}_{2}$ & 2.20 & $\mathrm{C}_{17} \mathrm{H}_{20} \mathrm{~N}_{4} \mathrm{O}_{10} \mathrm{~S}_{2}$ \\
\hline ES & 197.9864 & $\mathrm{C}_{7} \mathrm{H}_{5} \mathrm{NO}_{4} \mathrm{~S}$ & 1.27 & $\mathrm{C}_{7} \mathrm{H}_{5} \mathrm{NO}_{4} \mathrm{~S}$ \\
\hline GS-SE-ES & 305.0673 (by subtraction) & $\mathrm{C}_{10} \mathrm{H}_{15} \mathrm{~N}_{3} \mathrm{O}_{6} \mathrm{~S}$ (by subtraction) & - & $\mathrm{C}_{10} \mathrm{H}_{17} \mathrm{~N}_{3} \mathrm{O}_{6} \mathrm{~S}$ \\
\hline
\end{tabular}

Table S5. Measured $m / z$ and MFG results for the unknown derivative.

\begin{tabular}{cccc}
\hline Ion Species & Measured $m / z[\mathrm{M}-\mathrm{H}]^{-}$ & Molecular Formula (MFG) [M] & Difference (ppm) \\
\hline Unknown-SE & 405.0058 & $\mathrm{C}_{13} \mathrm{H}_{14} \mathrm{~N}_{2} \mathrm{O}_{9} \mathrm{~S}_{2}$ & 2.4 \\
ES & 197.9858 & $\mathrm{C}_{7} \mathrm{H}_{5} \mathrm{NO}_{4} \mathrm{~S}$ & 4.3 \\
Unknown-SE-ES & 207.0200 & $\mathrm{C}_{6} \mathrm{H}_{9} \mathrm{NO}_{5} \mathrm{~S}$ & 0.77 \\
\hline
\end{tabular}

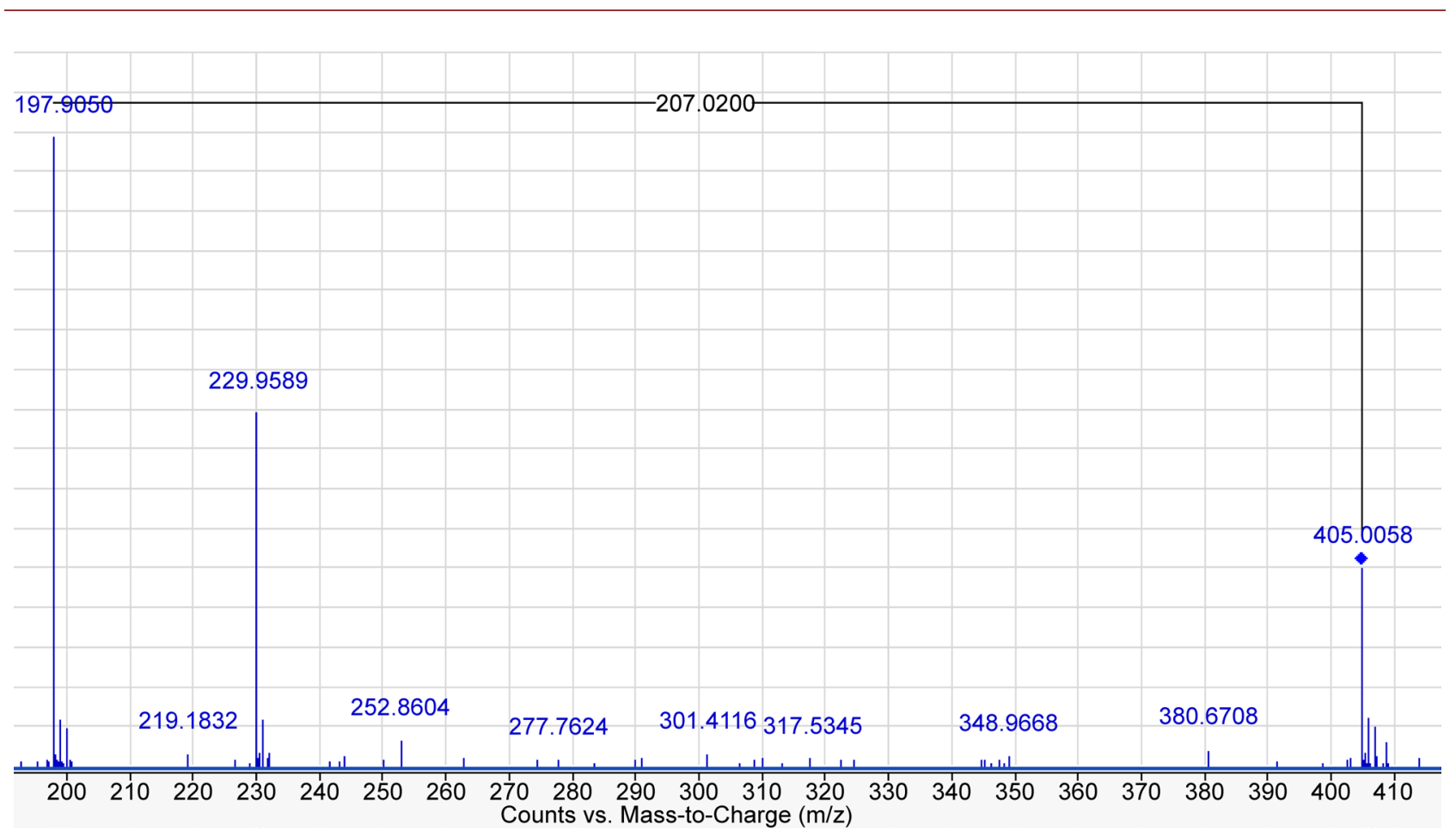

Figure S3. MS fragmentation spectrum of unknown derivative.

The results showed that the molecular formula for the unknown thiol species is proposed to be $\mathrm{C}_{6} \mathrm{H}_{11} \mathrm{NO}_{5} \mathrm{~S}$ after the addition of two protons to account for bond cleavage and negative ionisation.

\section{b) Positive ion mode MS Analysis}

For illustration, a list of the corresponding molecular ions and fragments observed by MS with source fragmentation from a mixture of standard RSSE's is given in Table S6. These results confirm the identity of the standard thiol RSSE's. 
Table S6. Corresponding molecular ions and fragments by positive mode MS analysis.

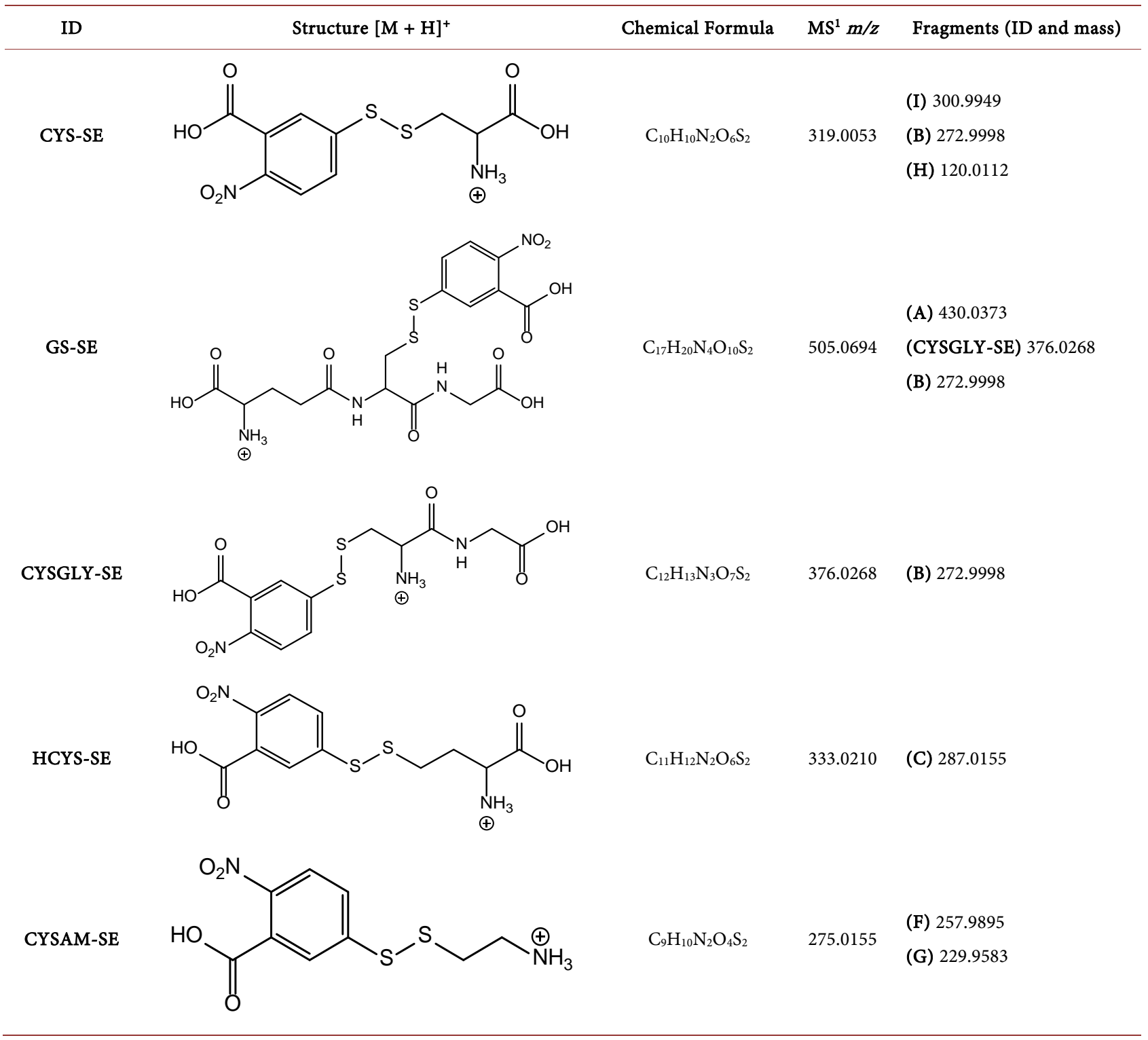

\section{Abbreviations}

CYS: L-cysteine; CYSGLY: cysteinylglycine,; CYSAM: cysteamine; ES: 5-thio-2nitrobenzoic acid; ESSE: 5'5 dithiobis(-2-nitrobenzoic acid); DTNB: 5'5 dithiobis(-2-nitrobenzoic acid); HCYS: homocysteine; LMWT: Low molecular weight thiols; GSH: glutathione; PCa: prostate cancer; TCA: trichloroacetic acid; TIC: total ion count. 
Submit or recommend next manuscript to SCIRP and we will provide best service for you:

Accepting pre-submission inquiries through Email, Facebook, LinkedIn, Twitter, etc. A wide selection of journals (inclusive of 9 subjects, more than 200 journals)

Providing 24-hour high-quality service

User-friendly online submission system

Fair and swift peer-review system

Efficient typesetting and proofreading procedure

Display of the result of downloads and visits, as well as the number of cited articles Maximum dissemination of your research work

Submit your manuscript at: http://papersubmission.scirp.org/

Or contact ajac@scirp.org 